\title{
SEEING ONCE IS BETTER THAN HEARING A HUNDRED TIMES
}

by Alex McAndrew

University of Sydney

\section{"WER DEN DICHTER WILL VERSTEHEN \\ MUSS INS DICHTERS LAND GEHEN" - Goethe}

Comparative literature can tell us so much; the instant communication of today can inform us so readily; yet there is nothing like the chance of assessing the real thing for oneself, to study one's field in depth without the aid of somebody else's tinted spectacles. Another real value accruing from a study-tour is the easy assessment one is able to make of one's own achievements at home. For these reasons I would like to express my sincere gratitude to the Senate for their granting of my study leave and to those colleagues who acted in my stead during this privileged absence.

The aim of my study-tour was three-fold: firstly to investigate my field of language laboratories and audio-visual education; secondly to visit Language Centres in Central Europe (having studied the main British and French ones in 1970); lastly to refresh my knowledge of European languages by residence in Europe and to immerse myself in Japanese life in order to come to a better appreciation of Japan, the Japanese and the Japanese language.

The European circuit entailed thousands of kilometers of travel and involved visits to universities, institutes and firms from Brussels to Hanover, from Zurich to Oslo. Warm welcomes were extended to me everywhere particularly at the University of Erlanger-Nurnberg by Professor Eric Bauer who has fond memories of his former post at Monash University and who is very enthusiastic about exchange software and personnel from Australian Universities.

My main interest lay in visits to the newly established language centres of the Federal Republic of Germany detailed later on in this report, yet I was in a position to make some general observations on educational tendencies in this land. Although Germany was the first country in the world to adopt a national education sysem, it has generally been traditional in its teaching techniques, conservative in its attitude to new ideas. Today, eduction is in transition. The new era of learning is based on the general belief that the future of the country 
depends upon education, that the needs and demands of the technological age must be met in the schools. The need for reform in tertiary institutions is undisputed but the progress is uncertain. The principle that the privilege of higher education is now the right of every citizen is not being fully carried through, for the introduction of NUMERUS CLAUSUS or quota system virtually negates the reforms that had been achieved in recent years. On the other hand there are signs that far too many students are studying more for prestige than from inclination.

In the schools the introduction of the GESAMTSCHULE (comprehensive school) is gradually being inplemented: under this reform the CENTRAL HAUPTSCHULE, the Science REALSCHULE and the liberal GYMNASIUM are being housed under the one roof, as are Universities, Teachers' Colleges and Universities of Technology (Gesamthochschulen) at the tertiary level. There are moves for a five-day week instead of the traditional six, and long vacations are staggered in the various LANDER on a roster system for the simple but sensible reason to attempt to equalize the traffic on the AUTOBAHNS in the summer months. LANDER in the BUNDERSREPUBLIK are spending more than a third of every mark on education. The expenditure upon modern equipment is prodigious. The old chalkboards are being replaced by projection screens and overhead projectors. The wooden benches for pupils are giving way to mobile desks with swinging panels and monitors: teaching and learning aids are incrcasing: T.V. cameras, daylight projectors, writing machines, film and sound cassettes, language laboratories, computers . . . In Western Germany the triple alliance of optics, acoustics and electronics is the beginning of their modernisation of schools.

My tour of Japan, limited to Tokyo, Saitama and Nagano prefectures, proved of great interest linguistically and culturally, but professionally not as rewarding as anticipated, there being practically no visible advancements in methodology or educational technology. It was easy to believe the story often told about the Japanese language professor who opposed all advancements in methodology on the grounds that a certain number of incomprehensible lectures was necessary to keep the student in his place. Many language laboratories were beautifully equipped with TV monitors in each student booth but there was little evidence of any effective use of this visual aid. The same can be said for computerized instruction often thoroughly reported in comparative literature. It must also be stressed for the academic visiting the Land of the Rising Sun that, organizing an itinerary prior to departure from Australia or even once in Japan 
itself, is a most difficult, nay, frustrating experience, unless it could be negotiated at the highest echelons of the educational or diplomatic circles or through a competent Japaness academic with Australian or international experience.

\section{DIDACTA 1974}

My atiendance at the 12th DIDACTA European Fair held in the GRAND PALAIS DU CENTENAIRE in Brussels (June 10th to 14th) provided a unique and convenient opportunity to inspect and compare educational hardware and software from Britain, Eastern and Western Europe and North America. DIDACTA also afforded the chance to participate in a conference of leading continental educators where current problems, trends and new methodologies were discussed. Attendance at DIDACTA is a must for any audio-visual enthusiast who might happen to be in Europe in early summer. In 1975 DIDACTA will be held in NUREMBERG, in 1976 BASLE will be the venue and 1977 HANOVER.

\section{TECHNICAL ADVANCEMENTS}

1974 saw no revolutionary technical innovations, rather a consolidation and better application of earlier hardware. On the audio side the tendencies are in a word more HUMANIZED, answering a need which has been increasingly felt in Australia in recent years. The hardware for both teacher and student has become more simple and didactically designed for the reeds of the users without emphasizing the technics behind it. Student controls are few: the audio machine is generally not in sight leaving the student much more desk space than formerly. There is a strong tendency to climinate the booth-like situation (except for library study) and present an open classroom, restoring the traditional visual and social link between teacher and student. This has been made possible by the introduction of improved noise-cancelling microphones with a recording range of about $50 \mathrm{cms}$. The trend fcr all tape recorders to be out of sight and touch of the students not orly reduces the fear of technology but changes the traditional laboratory into an electronic classroom where the electro-magnetic aids can be used where relevant in a face-to-face teaching learning situation. In short, no longer does the electronic technology dominate the scene and sterilize the atmosphere. Another grand advantage of the best European hardware is the ability to fastcopy from the console to all student machines simultaneously at twice or four times the normal student speed of $9.5 \mathrm{c} / \mathrm{p} / \mathrm{s}$. Language Laboratories using the compact cassette are far more accepted in Japan than in Europe, although quite a few but not all of the major European manufacturers have produced cassette laboratories. 


\section{Seeing Once}

In recent years the feasibility of the use of compact cassettes for language laboratories has been studied and quite a few manufacturers have; produced reliable heavy-duty hardware for everyday student use. There is no longer any lack of good hardware. The only doubt remains with the compact cassette itself, which, though greatly improved since its inception more than a decade ago, is still largely for amateur consumer use. The advantages of a cassette are many: simplicity, economy, storage, compatibilty with home machines; but because it does have definite mechanical disadvantages and is perhaps critically small (for the various tracks of audio information including high frequency pulses for visual devices and suitable separation of these tracks). Against the introduction of compact cassettes into language laboratories which, incidentally, would mean the copying of the whole of one's existing repertoire of library tapes (the master tapes would generally remain on open reels), there have been two distinct European arguments.

Both arguments embody the principle of retention of $6.3 \mathrm{~mm}(1 / 1 ")$ tape at a speed of no less than $9.5 \mathrm{c} / \mathrm{p} / \mathrm{s}$ (as against the $3.15 \mathrm{~mm}(1 / \mathrm{s}$ ") tape at $4.75 \mathrm{c} / \mathrm{p} / \mathrm{s}$ or compact cassettes). The first is provided by the UNISETTE produced by BASF and already used professionally in radio stations and the like. It is a cassette using $1 / 4$ " tape which has many built-in features superior to those of the compact cassette. With tape guidance being controlled by the machine, the UNISETTE is virtually fool-proof. The cost of this cassette, however, is at the moment eightfold that of compact cassettes. It would naturally require new (at present non-standard) machines to play them and there would be no compatibility with students. Although some firms are prepared to market language using UNISETTES, it would seem wise to consider purchase only when the UNISETTE becomes an internationally accepted standard and therefore less expensive.

The second argument against the compact cassette is afforded by certain laboratories which do not require the student to do any handling of the tape at all, the open reel deck being remote and secure from interference. For the pre-duplication of class tapes, which is a huge requirement in our own complex, there is a facility for copying the teacher's tape at the console onto all student tapes simultaneously at a fourfold speed of $38 \mathrm{c} / \mathrm{p} / \mathrm{s}$. For students who require a copy of the class programme for home study there is an output socket from which the student can tape onto his own cassette machine and his own compact cassette. This possibility is a decided test of the student's keenness and diligence and a protection against theft of University tapes.

The latter system would seem to be admirably suited to our own needs for instructional laboratories. On the other hand there would be a problem in the area of the use of open reels for library areas for in- 
dependent study. Here the choice would be the retention of the openreel deck to be loaded by the student or the installation of cassette equipment and with it the herculean task of copying each and every one of the thousands of open-reel tapes in the audio visual library, or the retention of the open-reel system with the possibility of rack mounting all of the library tape decks in a central cabinet.

Though there is general belief in a trend towards a multi-media approach in the teaching of foreign languages in both Europe and Japan, extravagant use of audio-visual aids was not in evidence; there were sensible views that audio-visual should be considered not as the end goal but simply as a better means to reach the goal.

In Europe, 1974 was the year of the VIDEOCASSETTE, marked by manufacturers, it is said, only after the market in domestic colour television had reached its climax. Videocassettes were being preferred to videotapes in most institutions visited, peripheral use only being for language study. The greatest advantage of the video (cassette or open reel) remains its convenience as a replacement of moving films. There seemed to be no great lack of software especially for English, and theoretically all materials available in movie films are potential software for video. One considerable problem is that the various types of colour video software based respectively upon PAL (German) SECAM (French and Russian) and NTSC (American and Japanese) systems are not compatible with one another.

In Japan educational TV from NHK in particular, with 126 educational TV hours per week, is very strong and well received by young Japanese who are so addicted to TV generally that a new word in the language, TELEBIKO (TV child), has been introduced. In the classroom the biggest disadvantage of TV still lies in the smallness of the screen. The promise of big-screen video monitors has not yet been fulfilled. For mass audiences in huge lecture halls there is general disenchantment with the small image. In Japan the size of student monitors was even smaller than in Europe. Quite a few language laboratories in Japan had attractive installations of individual TV monitors in the student booths but there was little evidence of any successful application since any programme broadcast was received by all students at the same time. The possibility of individual control would need the provision of video cassettes and a carousel of recorders for the whole group.

The VIDEO LONG PLAY DISC produced by Philips is a brilliantly conceived system. The projected cost of a video disc carrier is about the same as a colour TV receiver, whilst that of a video disc only about one dollar. One strorg advantage of the VLP disc over the video tape and video cassette recorders is that the image when "frozen" is just 


\section{Seeing Once}

as it is in motion. The disc, encased in plastic, is dust-proof and virtually damage-proof, its programmed modulations being read, not by mechanical means, but by laser light from the under side of the disc. Thus without friction, it docs not wear. Random access is possible within a split second at a specd of 1500 revolutions per second. Other similar European and American systems such as the German TELDEC and SELECTAVISION from R.C.A. that showed great promise in 1970 seem to have failed. Philips VLP disc system is due to be marketed in the consumer field in 1976 or 1977 . For use in education specialized software would be required but a great deal of consumer software could be edited onto taped VIDEO programmes in the same way as cuts are made for comprehensive audio programmes from audio discs.

In Japan one notable novelty from the SONY Corporation viewed at the 1974 Eledtronins show in Tokyo was the MAVIVA or MAGINETIC VIDEO CARD measuring $16 \times 21.5 \mathrm{~cm}$ which permits both recording and playback of audio-visual elements and has the advantage of being able to be used time and time again. Slow, back and freeze motions are also possible during production of programme. Plans for commercial production of MAVICA hardware and software have not yet been announced.

One audio-visual innovation of great promise seems to be the Audio-card from Revox which uses 60 MICROFICHES on a film the size of a normal postcard and is linked with a programmed audio-tape or cassette or with other programming machines. The pictures can be presented singly or programmed in a series in any order forwards or backwards, any picture being able to be selected within a fraction of a second. The problem of other similar tapepicture systems, the inability to regress and retain synchronisation of sound and image, has been solved by the Rovx Audiocard a step in the right projection!

In the wake of Philip's P.I.P. automatic audio-visual unit, BASF have produced the system 5000 which attempts to offer audio-visual in both motion or still form by using a KOMBIKASSETTE containing super-8 film and magnetic tape as well as a magnetic disc storage for the recording of student responses. There is also provision for the student to make written responses which remain unalterable once he proceeds to compare them with the programme answers. In addition to the programmed teaching and learning unit, the BASF 5000 system includes all the essential production units for production and coding of pictures, and programming of sound. This unit would be suitable for a full Learning Resources Centre or Audio Visual Division well endowed with funds.

Each visual or audio-visual medium has its own advantages and disadvantages, but for meaningful learning individually or in small groups, the simple still in the form of coloured slide combined with 
audio tape still ranks high, it is comparatively economical and flexible and allows greater control by the student.

We are all involved in a quest for the best whether it is textbooks, courses or electro-magnetic aids. There is no doubt that in recent years HARDWARE has improved. SOFTWARE too has improved, but the third and most imporrtant part in the present-day educational triangle remains the enigmatical HUMAN element which is the one which constantly and rightly seeks improvement in the other two sides. The questions remain: Will the student continue to blame the machine, the programme or the teacher without serious efforts of his own to reach his goal? Will the teacher calmly dismiss educational technology but none of his own inadequacies, Or will he strive to derive the best benefits from the means available?

\section{LANGUAGES CENTRES IN EUROPE}

In Western Europe there are about 60 Language Centres half of which have sprung up in the Federal Republic of Germany only in the last four or five years. The main reasons for their development are:

1. A renewed interest in foreign languages and their dissemination. In the quest for a United Europe, linguistic barriers must be removed.

2. The recognition of linguistics and its application to courses: the need for reform in the traditional ways of language teaching.

3. The need for "non-philologists" to learn languages.

4. The availability of educational technology of the language laboratory and other audio-visual media.

Most Language Centres have something in common: nevertheless each bears its definite characteristics and answers its own needs. Quite a few like the Ruhr University in Bochum, Erlangen-Nurnberg and Stuttgart are heavily weighted towards Applied Linguistics after the models of Besancon, Utrecht and Essex rather than after the style of Brussels, Louvain and Liege which specialize in audio-visual intensive courses for nonphilological foreign students. Some centres serve not only Modern Languages Seminars but also Institutes for Simultaneous Translation. In general, however, the language centres do stress the practical side of foreign language knowledge, the study of applied linguistics, courses for non-philological students and the use of the latest technical aids to teaching and learning. It is interesting to note that most Language Centres have grown out of existing Language Laboratories.

In non-university institutes there is a growing move away from perfectionism in the full oral and written command of language which can only be attained by relatively few devotees specializing in one language. There is a challenge to the standard set by the philologists 


\section{Seeing Once}

and a move to one that is reasonable and attainable. Hence the tendency to study several languages for understanding with proficiency, and so providing a firm basis for specialization in one later on. The argument presented is that an early decision for specialization in one language may be the wrong one.

In the past the problem has arisen of identification of language laboratories with one particular type of teaching, with inffexible classrooms and methodology associated with them. In fact the image of the languages laboratory has been over-projected and has been soundly and rightly criticized as not possessing the magical qualities assigned to it by wishful thinkers. For this reason alone a change in the name of our Language Laboratories to Language Centre is earnestly recommended. The Centre can extend language services, to prevent any clash between the two technologies, the literate and the electromagnetic and marry both for the common good. Although this recommendation is influenced by tends in Britian and Europe, it is based upon long felt needs in this direction. Already some Universities in Australia have Language Centres that have grown out of Language Laboratories. Our complex is big enough, central enough and already possessing many qualities of a Language Centre. It is difficult, for example, to find anywhere in the world an audio-visual library service for individuals to match that offered by our University Language Laboratories. A proving ground for Applied Linguistics, translation advisory service, courses for "non-philologists," experimental courses to test future A.U.C. recommendations, courses in the continuing education of teaching and learning ... all of these and more fairly lie within the scope of a Language Centre.

DIRECTOR LANGUAGE LABORATORIES ALEX MCANDREW 